\title{
Time Perception among the Youth and Its Implication for IndUSTRY: An EXPLORATORY STUDY
}

\author{
G G Rousseau \\ Department of Industrial Psychology, University of Port Elizabeth \\ D J L Venter \\ Department of Mathematical Statistics, University of Port Elizabeth
}

\begin{abstract}
The main objective of this exploratory study was to investigate perceived cultural differences in the perception of time among the youth and its implications for time management and productivity regarding future employment in industry. The study further sought to develop a reliable instrument for measuring time perception across cultures. A non-probability convenience sample $(N=467)$ was drawn from English, Afrikaans and Xhosa speaking respondents, aged 13 to 18 years. Results confirmed four factors: time allocation, time economy, time attitudes and scheduling of tasks. Significant differences between age, language and gender groups on time perception were observed. These findings have implications for time management training among the youth as well as for industry seeking employees who can perform tasks with speed and efficiency. Further refinement of the instrument in follow-up studies is essential.
\end{abstract}

JEL J22, M51

\section{Introduction}

The importance of utilising time efficiently is certainly not a novel idea. In 1757 Benjamin Franklin wrote that "time is money". Beyond doubt, one of the most salient characteristics of life in the beginning of the $21^{\text {st }}$ century is the frenetic pace of activities and tasks, driven by a relentless clock, particularly in Western cultures. Time saving devices such as computers, faxes, e-mail and cell phones are increasingly becoming indispensable parts of our work and personal lives. Marketers are focusing on timeconscious cravings of consumers with instant coffee, instant photos and instant foods, while organizations and industry value time-urgent individuals who can work under immense time pressures to meet deadlines (Landy \& Conte, 2004).

Many individuals today consider speed and efficiency in their jobs to be signs of success, especially those striving towards leadership positions. One of the main criteria for effective leadership and a successful career is the way individuals perceive and manage their time. A successful leader will spend huge amounts of his/her time solving problems, mobilising others and encouraging unconditional commitment to excellence. A successful team member of a work group, able to function well under deadline pressures will be one who can achieve much in as little time as possible. How well prepared are the youth for these future career demands and leadership challenges in terms of their present time perception and time management abilities? What are the time horizons and ways of thinking about time amongst the youth? These are some of the issues that need to be addressed by social researchers concerned about career success and leadership potential in the global labour market (Schuitema, 1998).

\section{Time perception and culture}

Time perception is the way people feel, experience and evaluate time. Several 
researchers (Van der Reis, 1997, Morello, 2000, Rousseau \& Venter, 2003) have shown that time is perceived differently by various cultural and socio-demographic groups. Van der Reis (1997) states that in some African cultures time is experienced in terms of basic distinctions between events that have happened and events that have not occurred. In tribal life an all embracing time is equated to life in natural terms.

Morello (2000) in a cross-cultural study on time orientation observed different perceptions about the future among Cuban, Spanish and Italian students. Cuban students declared that the future looked brighter than the past compared to the Italian and Spanish groups. Rousseau and Venter (2003) found that older consumers (above 50 years) were more concerned with a structured routine in their daily lives than consumers younger than 40 years. English speaking respondents were also more concerned with completing a task at a certain point in time (present orientation) than were Xhosa speaking respondents.

Time-use patterns have been studied by economists, developmental psychologists and students of mass communication (Juster \& Stafford, 1985; Robinson \& Godbey, 1997; Hudson, Wright, Marquis \& Green, 1999). These studies focused mainly on adult time use, designed to understand the relations among work, family and leisure and based on the hypothesis that time represents a form of capital to be expended by individuals. By extension, time perception among the youth can be viewed as an investment in opportunities for learning how to manage their time effectively at an early age and prepare for a successful career or leadership role in the world of work. Understanding how young people spend their time can also assist in developing sound social relationships and coping skills, necessary to deal with stress in their daily lives and future careers.

\section{Time expenditure among the youth}

In the past decade consumer and leisure behaviour patterns among the youth have become a high focus area for marketers in South Africa. It is estimated that there are approximately 16.5 million children in the country of whom 12.9 million are school going, representing a disposable income in excess of R4 billion annually in terms of spending money received from parents (Mulrooney, 2001). Adolescents constitute a large specialised market segment for clothing, confectionery, cosmetics, toys and sporting goods. They also play an important role in family buying behaviour and in many cases are the sole decision makers (Du Plessis \& Rousseau, 2003). It is therefore not surprising that market research should focus on how children spend their time, especially with regard to television viewing, shopping and recreational activities.

Huston, Wright, Marquis and Green (1999) found that children in the USA spend a considerable time eating meals, snacks and engaging in personal care (bathing and dressing) and smaller amounts of time doing chores of work in and outside the house, socialising with others, attending church, organised sport and outdoor unorganised play or hobbies. A major exception though, was passive leisure activities such as TV viewing and listening to the radio or music. The latter activities made up a large part of casual time, spent. The authors conclude that because TV is readily available, children take the path of least resistance in their choice of everyday activities. Time spent reading as well as social interaction and physical activity therefore become secondary preferences.

With regard to stereotyped expectations differences regarding age and gender in time spending, patterns appear to be greater among older children (12 to 18 years) than among younger children (3 to 11 years). Mauldin and Meeks (1990) found that girls spent more time in household work, personal care, shopping and errands whereas boys spent more time in unstructured leisure activity, sports and outdoor activity.

Mutz, Roberts and Van Vuuren (1993) observed among adolescents in South Africa, no relationship between a change in TV viewing and reading. Decreases in TV viewing had a slight tendency to predict increases in time spent in sports and clubs. The authors did, however, found that adolescents spent less time in outdoor 
activities and social activities away from home after TV was introduced in South Africa. From the above it seems that children who have talent or skills in reading, sport or social activities or who have opportunities for playing outside, being with peers or participating in other similar activities, may watch little TV, as a consequence.

Although no literature could be found on time spent in doing school home work after normal school hours, marketers have turned their attention to launching high school youth empowerment programmes. A life skills programme comprising of various modules pertaining to personal finance and taxation, career guidance, health and grooming has been recently launched in five high schools in Gauteng, South Africa (Du Plessis, 2003). These initiatives demonstrate how keen marketers are to get involved with the youth's life style and time expenditure patterns in order to communicate more effectively with them through the media.

\section{Time management among the youth}

Although the popular literature on time management (Taylor \& Mackenzie, 1986; Macan, 1994) claims that engaging in time management behaviours result in increased task performance, satisfaction and lower stress levels, little is known about the youth's ability to manage their time. Traditional time management focuses on "doing more in less time" which may not always appeal to the youth's carefree, layback and "cool" lifestyle. Du Plessis (2003) report that the South African youth are less inclined to care about crime, unemployment, poor economy, education and homelessness but more inclined to worry about AIDS and family abuse.

Nevertheless, young people do experience stress in their school performance and social relationships, often due to poor time management. Therefore, it is important for young people at an early age to learn to take responsibility for their stress levels by implementing time management techniques, increasing physical exercise and expanding their social support network (Robbins, 2001). Understanding and utilising time management principles can help young people to better cope with tensions created by school work and social demands. The following time management principles are suggested by Robbins (2001): Students should make daily lists of activities to be accomplished. These activities need to be prioritised by importance and urgency. Activities should subsequently be scheduled according to the priorities set. Students should also know their daily routine and complete the most demanding tasks during the high part of their cycle when they are most alert and productive.

Covey (1992) argues that all activities can be typified as either urgent or not urgent, on the one hand, and important or not important on the other. Most people, according to the author, spend their time on activities that are urgent and important. Such activities include dealing with crises, handling deadline-driven projects and pressing problems. Consequently, these people suffer from stress and burnout as they practice crises management. However, people who focus their energy on activities that are important but not urgent have vision, perspective balance, discipline and few crises. This is because they occupy themselves with non-urgent matters such as prevention, relationship building and planning (Covey, 1992).

Tertiary institutions in South Africa such as the University of Stellenbosch and the University of Port Elizabeth have recognised the importance of developing time management and study skills among their students. Counselling services at these institutions as well as student diaries focus on providing information to assist students with time management and planning their student life on campus (Baatjies, 2003). Time management behaviours such as goal setting and prioritizing activities appear to have beneficial effects if they give people the perception that they have control over their time. Macan (1994), however, found that contrary to popular claims, time management training was not found to be effective in the organisation where he performed a study. This does not however invalidate the advantages of time management training, especially among the youth who are 
generally more susceptible to learning new skills.

Carter, Kravits and Vaughan (1995) have successfully implemented time-management programmes among school children as part of a career tool kit. These authors state that since time resists control because it remains constant, young people must learn that instead of trying to control it, they should rather plan to make the best of the time available for completing a task. Procrastination is time management's enemy number one! In their training programme the authors teach children to ambush procrastination by (a) asking for help with projects or school work, (b) remembering that no one does anything perfectly and (c) thinking positively about themselves and about completing a task. Setting reasonable goals and writing them down also forms part of the time management training.

From the above brief overview it seems reasonable to suggest that there is ample scope for exploring time perception and time spending among the youth in South Africa. The main objective of this study was therefore to investigate time perception among the youth and to explore its implications for time management and productivity regarding future employment opportunities in industry. A secondary objective of the study was to develop a reliable instrument for measuring time perception cross-culturally. Due to the exploratory nature of this study no specific hypotheses were formulated.

\section{Method}

An item scale developed and used in previous studies (Venkatesan \& Schroeder, 1996; Morello, 2000) was modified for application in South Africa. The Likert scale was increased from a three to a five point verbal anchored rating scale as suggested by Malhotra (1999). The first 32 items focused on respondents' perceptions about spending their time and measured the following four factors: scheduling of tasks, time allocation, attitudes towards time and economy of time. Scheduling of time refers to monochronism or M-time versus polychronism or P-time, i.e. doing things one at a time as opposed to being involved in a multitude of activities at the same time. Time allocation refers to the fact that people spend their time differently and have different priorities. Attitudes towards time refer to perception of temporal dimensions of time, for instance orientations towards the past, present and future. Economy of time refers to the fact that time can be regarded as a scarce source or as indefinitely available. Respondents rated the extent to which they agreed or disagreed with each of the 32 statements in the questionnaire.

This was followed by six sentence completion items measuring respondents' time orientations towards the past, present and future. Respondents had to complete each sentence by indicating the word "past", "present" or "future" in the spaces allocated on the questionnaire. The questionnaire concluded with measures of several demographic variables: home language, age, gender, education and monthly allowance. Prior to administering the questionnaire it was tested among a group of learners to ascertain whether they understood the wording of the questions. Although questionnaires were only available in English, it should be noted that Afrikaans and Xhosa speaking fieldworkers did the necessary translation where required.

\section{Sample}

A non-probability convenience sample $(N=$ 467) was drawn from English, Afrikaans and Xhosa speaking respondents aged 13 to 18 years. All the respondents were learners at a secondary high school in Port Elizabeth. The school enrols children from various cultural backgrounds. The sample used quotas to include respondents from grade eight to twelve, representative from all the language, gender and age groups in the school.

\section{Data collection}

Questionnaires were completed during school hours. Teachers acted as fieldworkers. They selected from each class a group of 25 learners, representative of different cultural backgrounds to complete the questionnaires during a 
practical period. The questionnaires were completed under strict supervision of the teachers who checked that learners understood the instructions and fully completed each questionnaire.

\section{Data analysis}

The BMDP programme 4M (Frane, Jenrich \& Samson, 1985) was used to perform factor analysis on the item sample. The method of principal component analysis was used with oblique direct quartimin rotation. After all attempts failed to find a stable factor solution in an analysis that includes all items, four separate analyses were conducted, one for each of the four factors derived by Venkatesan and Schroeder (1996). Cronbach's coefficient alphas were calculated to determine the reliability of scores derived from the measuring instrument (Table 1).

Descriptive statistics such as the mean and standard deviation, frequency distribution and Pearson Product Moment correlations were calculated by means of BMDP programmes 2D, $4 \mathrm{~F}$ and $8 \mathrm{D}$ respectively (Table 2 ). The BMDP program 1D was then used to calculate mean factor scores for the various socio-biographical variables and perceptions of the past, present and future. Program $2 \mathrm{~V}$ was then used to perform multi-variate analysis of variance (MANOVA) to investigate which of the sociobiographical variables were significantly related to the various time factors (Table 3 ). The BMDP program 7D was subsequently used to perform one-way analysis of variance to test the statistical significance of factor score differences between the various language, age and gender groups. These results appear in Table 4 . Significant post hoc Sheffé test results $(\mathrm{p}<0.05)$ and Cohen's statistics $(\mathrm{d}>0.20)$ are shown in Table 4.

\section{Results}

Factor analysis, using direct quartimin rotation and principal component extraction, was used to determine, for each of the four factors separately, the factor loadings of related items according to the structure reported by Venkatesan and Schroeder (1996). Results are reported in Table 1 .

Although all items loaded at an acceptable level of more than 0.30 on the applicable factor (with the exception of Q5 Time heals all wounds on factor 3 Attitudes towards Time) the other results are not satisfactory. Only the Cronbach's alphas on the first two factors were larger than 0.50 , the recommended minimum for exploratory studies, while the percentages of total variance explained are all well below the desired 60 per cent for social scientific studies. Statistics based on the factor scores should thus be treated with caution. Further research is required to modify the questionnaire so that it can be utilised to derive factor scores with acceptable validity and reliability.

\section{Table 1}

Factor analyses results $(N=434)$ : measures of time perception

\begin{tabular}{|lc|}
\hline Factor 1: Scheduling of Tasks & $\begin{array}{c}\text { Factor } \\
\text { Loadings }\end{array}$ \\
Q28. I plan each and every day & 0.769 \\
Q27. I am a very punctual person & 0.621 \\
Q30. I always schedule and preplan my shopping activities & 0.619 \\
Q24. I tend to do most things on a regular, scheduled basis & 0.599 \\
Q32. I have a great amount of control over how I spend my time & 0.556 \\
Q31. I always like to know how long a task will take before I begin & 0.555 \\
Q29. There is no excuse for being late & 0.544 \\
Q23. Interruptions to my planned routine tend to bother me & 0.400 \\
Percentage of total variance explained: 34.9\%; Cronbach's coefficient alpha: 0.73 & \\
\hline
\end{tabular}




\section{Factor 2: Time Allocation}

Q10. There never seems to be enough time to do the things I enjoy

Q11. Time lost can never be regained

Q09. I would like the pace of my life to be slower

Q21. I feel I have little control over my time

Q15. If I don't complete all I wanted to do in the day, I tend to feel frustrated

Q25. Managing one's time is an important key to success in life

Percentage of total variance explained: $30.8 \%$; Cronbach's coefficient alpha: 0.54

\section{Factor 3: Attitudes towards Time}

Q17. I rarely look at a clock or watch

Q18. I think of time as a circle

Q19. I spend little time thinking about the future

Q14. I spend little time thinking about the past

Q22. The past is more important than the future

Q20. The future goes on indefinitely

Q05. Time heals all wounds

Percentage of total variance explained: $23.9 \%$; Cronbach's coefficient alpha: 0.45

\section{Factor 4: Economy of Time}

Q06. I like to stay with a task until it's completed, regardless how long it takes 0.607

Q04. I treat time as a scarce resource

Q02. I like to spend time just talking with friends and family

Q03. When I'm enjoying myself, I tend to lose track of time

Q08. I frequently lose myself in what I'm doing and forget about time

Percentage of total variance explained: $28.5 \%$; Cronbach's coefficient alpha:

0.37

Table 2 shows descriptive statistics and correlations for the sample.

Table 2

Descriptive statistics $(N=467)$

\begin{tabular}{|c|c|c|c|c|c|c|c|c|}
\hline & & & \multicolumn{6}{|c|}{ Frequency distribution } \\
\hline & Mean & S.D & \multicolumn{2}{|c|}{ Low } & \multicolumn{2}{|c|}{ Average } & \multicolumn{2}{|c|}{ High } \\
\hline $\begin{array}{l}\text { Time perception } \\
\text { factors: }\end{array}$ & & & \multicolumn{2}{|r|}{$(\%)$} & \multicolumn{2}{|r|}{$(\%)$} & \multicolumn{2}{|r|}{$(\%)$} \\
\hline $\begin{array}{l}1.1 \text { Scheduling of } \\
\text { tasks }\end{array}$ & 3.30 & 0.72 & 66 & 14.1 & 192 & 41.1 & 09 & 44.8 \\
\hline 1.2 Time allocation & 3.79 & 0.66 & 21 & 4.5 & 113 & 24.2 & 333 & 71.3 \\
\hline $\begin{array}{l}\text { 1.3 Attitudes towards } \\
\text { time }\end{array}$ & 2.85 & 0.63 & 169 & 36.2 & 206 & 44.1 & 92 & 19.7 \\
\hline 1.4 Economy of time & 3.92 & 0.57 & 16 & 3.4 & 80 & 17.1 & 371 & 79.4 \\
\hline \multirow{2}{*}{$\begin{array}{l}\text { Attitudes re past, } \\
\text { present, future }\end{array}$} & \multirow[t]{2}{*}{ Mean } & \multirow[t]{2}{*}{ S.D } & \multicolumn{6}{|c|}{ No. of responses out of seven } \\
\hline & & & \multicolumn{2}{|c|}{$\begin{array}{c}\text { None / One } \\
(\%)\end{array}$} & \multicolumn{2}{|c|}{$\begin{array}{c}\text { Two/Three } \\
(\%)\end{array}$} & \multicolumn{2}{|c|}{$\begin{array}{c}\text { Four }+ \\
(\%)\end{array}$} \\
\hline 2.1 Past & 1.88 & 1.26 & 207 & 44.3 & 211 & 45.2 & 49 & 10.5 \\
\hline 2.2 Present & 2.60 & 1.35 & 95 & 20.3 & 263 & 56.3 & 109 & 23.3 \\
\hline 2.3 Future & 2.52 & 1.33 & 101 & 21.6 & 266 & 57.0 & 100 & 21.4 \\
\hline
\end{tabular}




\begin{tabular}{|l|c|c|c|c|}
\hline & Correlations & & & \\
\cline { 2 - 5 } & $\begin{array}{c}1.1 \\
\text { Scheduling } \\
\text { of tasks }\end{array}$ & $\begin{array}{c}1.2 \\
\text { Time } \\
\text { allocation }\end{array}$ & $\begin{array}{c}1.3 \\
\text { Attitudes } \\
\text { towards time }\end{array}$ & $\begin{array}{c}1.4 \\
\text { Economy } \\
\text { of time }\end{array}$ \\
\hline $\begin{array}{l}\text { Time perception factors: } \\
1.1 \text { Scheduling of tasks }\end{array}$ & - & & & \\
1.2 Time allocation & $0.220^{*}$ & - & - & \\
1.3 Attitudes towards time & $0.200^{*}$ & $0.172^{*}$ & & \\
1.4 Economy of time & $0.179^{*}$ & $0.284^{*}$ & $0.172^{*}$ & \\
\hline Attitudes re past, & & & & \\
present, future & & & & \\
2.1 Past & 0.074 & 0.069 & $0.093^{*}$ & 0.041 \\
2.2 Present & -0.070 & -0.061 & $-0.095^{*}$ & $-0.097 *$ \\
2.3 Future & 0.001 & -0.003 & 0.008 & -0.097 \\
\hline
\end{tabular}

* Significant at .05 level $(r>=0.091)$

The majority of the respondents, 79.4 per cent and 71.3 per cent respectively, obtained high (greater than 3.4 on a 1 to 5 scale) Economy of Time and Time Allocation scores indicating their awareness of the importance of carefully managing time as a scarce resource. Attitudes towards Time obtained the lowest mean factor score of 2.85 which is marginally above the 2.60 lower threshold of the Average category. Based on this and the fact that more than a third (36.2 per cent) of the respondents obtained low scores for this factor, it would appear that the youth does not have strong attitudes towards time as an entity.

The results for the seven sentence completion test are inconclusive to determine a preference among the youth for the past, present or future with only 10.5 per cent who referred to the past in four or more cases, while the minority, 23.3 per cent and 21.4 per cent respectively, referred to the present and future in four or more cases. Based on the mean scores one may conclude that the present and future are more important than the past for the population of youths represented by the sample.

Table 2 further shows that significant but relatively low positive correlations exist between the four factors. This implies a reliable relationship between the level of agreement among the four factors, e.g. that those respondents who agree that time allocation is important, are predominantly aware of the economy of time. Only three significant but very low coefficients were obtained for the correlation between the number of preferences for the past, present and future with the time perception factors. Although results should be regarded as inconclusive, it is interesting to note that the factor attitudes towards time, was positively correlated with a preference for the past but negatively with the present. This may imply that young people with a greater awareness of the past are also more aware of the importance of time as an entity. The other significant result seems to indicate that young people with an inclination towards the future do not regard the economy of time as an important factor in their lives.

To determine the relationships between certain socio-biographical variables and the time factors, multi-variate analysis of variance (MANOVA) was conducted. The results are summarised in Table 3.

From Table 3 it can be seen that home language and age are significantly related to attitudes towards time while gender is significantly related to time allocation and economy of time. With regard to perceptions of past, present and future, the only significant result was that gender is related to a preference for the present. 
Table 3

Results of Manovas to determine relationships between socio-biographical variables and factors

\begin{tabular}{|c|c|c|c|c|c|}
\hline \multirow[t]{2}{*}{ Time factors } & & Home language & Age & Gender & Income \\
\hline & df & 2.460 & 1.460 & 1.460 & 2.460 \\
\hline Scheduling of tasks & $\begin{array}{l}F \\
p\end{array}$ & $\begin{array}{l}0.46 \\
0.63\end{array}$ & $\begin{array}{l}0.52 \\
0.46\end{array}$ & $\begin{array}{l}0.62 \\
0.43\end{array}$ & $\begin{array}{l}0.06 \\
0.94\end{array}$ \\
\hline Time allocation & $\begin{array}{l}F \\
p\end{array}$ & $\begin{array}{l}0.07 \\
0.93\end{array}$ & $\begin{array}{l}0.12 \\
0.72\end{array}$ & $\begin{array}{l}4.47 \\
0.03^{*}\end{array}$ & $\begin{array}{l}1.13 \\
0.32\end{array}$ \\
\hline Attitudes towards time & $\begin{array}{l}F \\
p\end{array}$ & $\begin{array}{l}3.49 \\
0.03 *\end{array}$ & $\begin{array}{c}10.15 \\
0.00^{* *}\end{array}$ & $\begin{array}{l}0.01 \\
0.93\end{array}$ & $\begin{array}{l}1.07 \\
0.34\end{array}$ \\
\hline Economy of time & $\begin{array}{l}F \\
p\end{array}$ & $\begin{array}{l}2.16 \\
0.11\end{array}$ & $\begin{array}{l}0.02 \\
0.87\end{array}$ & $\begin{array}{l}17.94 \\
0.00^{* *}\end{array}$ & $\begin{array}{l}1.73 \\
0.17\end{array}$ \\
\hline \multicolumn{6}{|c|}{ Perceptions of past, present and future } \\
\hline Past & $\begin{array}{l}F \\
p\end{array}$ & $\begin{array}{l}0.34 \\
0.70\end{array}$ & $\begin{array}{l}0.02 \\
0.89\end{array}$ & $\begin{array}{l}3.15 \\
0.07\end{array}$ & $\begin{array}{l}0.88 \\
0.41\end{array}$ \\
\hline Present & $\begin{array}{l}F \\
p\end{array}$ & $\begin{array}{l}0.32 \\
0.73\end{array}$ & $\begin{array}{l}1.02 \\
0.31\end{array}$ & $\begin{array}{l}6.65 \\
0.01 *\end{array}$ & $\begin{array}{l}0.17 \\
0.84\end{array}$ \\
\hline Future & $\begin{array}{l}F \\
p\end{array}$ & $\begin{array}{l}1.07 \\
0.35\end{array}$ & $\begin{array}{l}1.32 \\
0.25\end{array}$ & $\begin{array}{l}0.86 \\
0.36\end{array}$ & $\begin{array}{l}0.22 \\
0.80\end{array}$ \\
\hline
\end{tabular}

* significant at 0.05 level. ${ }^{* *}$ significant at 0.01 level

To better understand the nature and extent of the significant relationships:

a) Descriptive statistics by socio-biographic group were calculated,

b) Post-hoc Scheffé tests were conducted to determine the individual differences among the three language groups, and

c) Cohen's d statistics were calculated to establish the practical significance of the results.

Table 4 reflects the results.

\section{Table 4}

Anova: results by home language, age and gender

\begin{tabular}{|l|c|c|c|c|c|c|}
\hline Factors & $\begin{array}{c}\text { Socio-bio- } \\
\text { graphical } \\
\text { variable }\end{array}$ & \multicolumn{3}{|c|}{ Descriptive statistics } & \multicolumn{2}{c|}{ Post-hoc test results } \\
\cline { 2 - 7 } & $\begin{array}{c}\text { Home } \\
\text { language }\end{array}$ & English & Afrikaans & Xhosa & & \\
\cline { 2 - 7 } & Frequency & 277 & 125 & 65 & $\begin{array}{c}\text { Scheffé } \\
\text { p }<0.05\end{array}$ & $\begin{array}{c}\text { Cohen's } \\
\text { d }>0.2\end{array}$ \\
\hline Attitudes & Mean & 2.90 & 2.72 & 2.91 & & $1: 2$ \\
towards & S.D & 0.64 & 0.60 & 0.58 & $1: 2$ & $2: 3$ \\
\hline time & Age & $\mathbf{1 3 - 1 7}$ years & $\mathbf{1 8 +}$ & & & \\
\hline & Frequency & 401 & 66 & & & \\
\cline { 2 - 7 } & & $85.9 \%$ & $14.1 \%$ & & & \\
& & & & & & \\
\end{tabular}




\begin{tabular}{|l|c|c|c|c|c|c|}
\hline Attitudes & Mean & 2.89 & 2.61 & & n.a & $1: 2$ \\
\hline \multirow{4}{*}{ towards time } & S.D & 0.63 & 0.55 & & & \\
\hline & Gender & Male & Female & & & \\
\cline { 2 - 7 } & Frequency & 218 & 249 & & & \\
\hline Time & & $46.7 \%$ & $53.3 \%$ & & n.a & $1: 2$ \\
allocation & Mean & 3.71 & 3.86 & & n.a & $1: 2$ \\
\hline Economy of & S.D & 0.66 & 0.65 & & & \\
time & S.D & 3.80 & 4.01 & & n.a & $1: 2$ \\
\hline Perception of & Mean & 2.43 & 2.75 & & & \\
present & S.D & 1.35 & 1.33 & & & \\
\hline
\end{tabular}

The results reported in Table 4 are discussed below by socio-biographic variable.

\section{Home language}

The majority of respondents (59.3 per cent) were English speaking followed by Afrikaans (26.8 per cent) and Xhosa speaking respondents (13.9 per cent). The English group had significantly higher scores on average than the Afrikaans group with regard to attitudes towards time. The difference between the Afrikaans and the Xhosa group, although of the same magnitude and of practical significance, was not statistically significant.

\section{Age}

The respondents were predominantly under the age of 18 years (85.9 per cent). The only significant result was that the younger group (13 to 17 years) obtained a higher mean factor score than the older group with regard to attitudes towards time. Cohen's test confirmed the practical significance of the difference between the two age groups. This suggests that younger people are more aware of time as an entity.

\section{Gender}

There were more female ( 53.3 per cent) than male respondents (46.7 per cent) in the sample. Females obtained higher mean factor scores than males on time allocation and economy of time. In the sentence completion test females also obtained a higher mean score than males on perception of the present. These differences observed between the two gender groups were of practical significance according to Cohen's $\mathrm{d}$ statistics. The results may indicate that females are more time conscious compared to males.

These results, although tentative, suggest that differences do exist between language, age and gender groups among the youth with regard to time perception. It seems that Xhosa and English speaking youth hold stronger attitudes towards time than Afrikaans speakers. With regard to age the results also suggest that younger learners held stronger attitudes towards time than older respondents. It should, however, be remembered that only 19.7 per cent of the total sample scored high on this factor (Table 2).

With regard to gender groups the results suggest that females do spend their time differently from males and have different priorities (time allocation). They regard time as a scarce source (economy of time) and have strong perceptions about the present. These results support those of Mauldin and Meeks (1990) who also found differences in time spending patterns between gender and age groups in their study.

\section{Conclusion}

The main objective of this study was to investigate time perception among the youth and to explore its implications for time management and productivity regarding future employment opportunities in industry. A 
secondary objective was to test an instrument for measuring the construct cross culturally. Research suggest that a better understanding of how young people think about time and the way they spend it could pave the way for effective time management education and training at a secondary and tertiary level (Carter, Kravits \& Vaughan, 1995, Baatjies, 2003). Such programmes can prepare young people for successful careers in commerce and industry that demand critical time management skills.

Previous research on time management, (Morello, 2000; Rousseau \& Venter, 2003) suggest that time is perceived differently by various cultural and socio-demographic groups. It would, therefore, be logical to assume that young people form different cultural backgrounds would also hold different perceptions about time. In this exploratory study a non-probability convenience sample was drawn from respondents at a secondary high school in Port Elizabeth, representative of learners from various cultural backgrounds. A modified version of a questionnaire developed by previous researchers (Venkatesan \& Schroeder, 1996; Morello, 2000) was employed in the study.

Findings of the study confirmed four factors of time perception among the youth that need to be considered in a time management program. These were time allocation, time economy, time attitudes and scheduling of tasks. With regard to differences between sociodemographic groups the study showed significant differences between language groups on time attitudes. Practical significance was observed between age and gender groups on specific time factors.

In the sentence completion test results suggest that the past is the least important in terms of temporal time dimensions among the youth. No clear perceptions about the past, present and future emerged although it seems that young female respondents' perceptions of the present featured most prominently.

These tentative findings should, however, be treated with caution as a major concern in this study is the reliability of the measuring instrument. Low Cronbach's alpha scores on three of the subscales points to a lack of construct validity which may be caused by a lack of understanding of the items in the questionnaire, especially the Afrikaans and Xhosa speaking learners, or dishonest responses. It seems that strict supervision is required when administering questionnaires among high school learners. A follow-up survey with a revised questionnaire, available in English, Afrikaans and Xhosa, administered at more than one school, is therefore necessary to address some of the shortcomings of the present study.

Despite these limitations the study indicated that time perception and time management skills need serious attention at secondary schools if these institutions are serious about preparing the youth for the demands of the world of work. Many learners are unaware of the importance of time management for their future career success. One of the main criteria of successful leadership according to Schuitema (1998) is the ability to plan and manage one's time effectively. Learning at an early age to perform within available time limits can serve as a motivating and disciplinary force to realise personal goals in life.

Results further suggest that educators should be sensitive to cultural differences in time perception. Language and religion are important socio-biographical variables that may point to cultural diversity. The four time-perception factors identified in this study may further serve as guidelines for key focus areas in time management programmes.

Commerce and industry in which a fast work pace is crucial for timely development of new products such as in the computer industry, would need to pay more attention to time management skills. Time awareness and deadline control are essentials for success in these industries. Therefore young employees who can withstand high levels of time pressure when the work situation requires it, will be sought after candidates in these industries. Youngsters who have been exposed to time management programmes during their school careers can only benefit from such interventions as they would have acquired time management skills at an early age in their lives. 
Marketers promoting time saving products and services (e.g. instant cameras, quick release sporting gear, speed point banking services) should also consider sponsoring time management programmes at secondary and tertiary institutions. Such programmes may sensitise young consumers to the productive use of time through purchasing time saving devices which in turn may lead to an improved lifestyle and stress absent work environment.

\section{References}

1 BAAITJIES, R. (2003) UPE Diary, UPE Communication and Marketing Services: Port Elizabeth.

2 CARTER, C., KRAVITS, S.L. \& VAUGHAN, P.S. (1995) The Career Tool Kit: Skills for Success, Engelwood Cliffs, Prentice Hall Inc.: New Jersey.

3 COVEY, S.R. (1992) The Seven Habits of Highly Effective People, Simon \& Schuster Publishers: London.

4 DU PLESSIS, D. 2003) "A Marketing medium for youth", Marketing Mix, 05/03, System Publishers: Craighall.

5 DU PLESSIS, D. (2003) "The nerd herd or the cool elite”, Marketing Mix, 05/03, System Publishers: Craighall.

6 DU PLESSIS, P.J. \& ROUSSEAU, G.G. (2003) Buyer Behaviour: A Multicultural Approach ( $3^{\text {rd }}$ ed.) Oxford University Press: Cape Town.

7 FANE, F., JENRICH, R.I. \& SAMPSON, P.F. (1979) BMPD In W.J. Dixon and M.B. Brown (eds.) BMPD Statistical Software, University of California Press: Berkley.

8 HUSTON, A.C., WRIGHT, J.C., MARQUIS, J. \& GREEN, S.B. (1999) "How young children spend their time: Television or other activities", Development Psychology, 35(4): 912-25.

9 JUSTER, F.T. \& STAFFORD, F.P. (eds.) (1985) "Time, goods and well-being", Ann Arbor MI: Survey Research Centre. Institute for Social Research.

10 LANDY, F.J. \& CONTE, J.M. (2004) Work in the 21 $1^{\text {st }}$ Century, Mc Graw-Hill: New York, NJ.

11 MACAN, T.H. (1994) "Time management. Test of a process model", Journal of Applied Psychology, 79(3): 381-91.
12 MALHOTRA, N. (1994) Marketing Research: An Applied Orientation, (3rd ed.) Prentice Hall Inc.: New Jersey.

13 MAULDIN, T. \& MEAKS, C.B. (1990) "Sex differences in children's time use", Sex Roles, 22: 537-54.

14 MORELLO, G. (2000) "Time orientation across cultures: A comparative study in Italy, Cuba and Spain”, Proceedings: Multicultural Marketing Conference, Grand Stanford Intercontinental Hotel: Hong Kong.

15 MULROONEY, B. (2001) “Today's kids today's megaspenders", Marketing Mix, 18(3): 26-33.

16 MUTZ, D., ROBERTS, D.F. \& VAN VUUREN, D.P. (1993) "Reconsidering the displacement hypothesis: Television's influence on children's time use", Communication Research, 20: 51-75.

17 NUNNALLY, J. (1978) Psychometric Theory (2 $2^{\text {nd }}$ ed.) Mc Graw-Hill: New York.

18 ROBBINS, S.P. (2001) Organizational Behaviour ( $9^{\text {th }}$ ed.) Upper Saddle River, Prentice Hall Inc.: New Jersey.

19 ROBBINS, J.P. \& GODBEY, G. (1997) Time for Life: The Surprising Ways Americans Use their Time, University Press: Pennsylvania State University Press.

20 ROUSSEAU, G.G. \& VENTER, D.J.L. (2003) "A multicultural investigation of consumer time perception", Management Dynamics, 7 (2): 2432.

21 SCHUITEMA, E. (1998) Leadership, Ampersand Press: Cape Town.

22 TAYLOR, J. \& MACKENZIE, R.A. (1986) "Time is money, so use it productively", $A B S A$ Banking Journal, 78: 130-33.

23 VAN DER REIS, A.P. (1997) "African concepts of time", Between Tradition and Innovation: Time in a Managerial Perspective, ISIDA Study and Research Series, 14, Fabio Orlando Editore: Palermo.

24 VENKATESAN, M.V. \& SCHROEDER, J.E. (1997) "Time and consumer behaviour in different cultures", Between Tradition and Innovation: Time in a Managerial Perspective, ISIDA Study and Research Series, 14, Fabio Orlando Editore: Palermo. 